\title{
La música de Rainer Viertlböck en la versión restaurada del film Das Kabinett des Doktor Caligari, de Robert Wiene (1919)*
}

RAINER VIERTLBÖCK'S MUSIC IN THE RESTORED VERSION OF THE FILM DAS KABINETT DES DOKTOR CALIGARI BY ROBERT WIENE (1919)

A MÚSICA DE RAINER VIERTLBÖCK NA VERSÃO RESTABELECIDA DO FILME
DAS KABINETT DES DOKTOR CALIGARI DE ROBERT WIENE (1919)

Anna Amorós Pons** Nuria Gómez Otero***

Cuadernos de Música, Artes Visuales y Artes Escénicas

/Volumen 12 - Número 2 / Julio - Diciembre de 2017

/ ISSN 1794-6670/ Bogotá, D.C., Colombia / pp. ' $x x^{\prime}$

Fecha de recepción: 31 de marzo de 2016

Fecha de aceptación: 8 de agosto de 2016

Disponible en línea: 22 de junio de 2017

doi:10.11144/Javeriana.mavae12-2.mrvv

* Artículo de investigación. Se enmarca dentro de la Línea de Investigación de Doctorado "Cine y artes plásticas, expresionismo / narrativa cinematográfica" (prof. dra. Anna Amorós Pons, IP Grupo I+D CS2), Programa de Doctorado Publicidad, Relaciones Públicas y Comunicación Audiovisual (Universidad de Vigo, desarrollado entre 2005-2010, con resultados científicos [DEA, tesinas, tesis]).

* Doctora en Ciencias de la Comunicación. Profesora titular de Comunicación Audiovisual y Publicidad, especialidad Cine, de la Universidade de Vigo (Vigo, España).

** Doctora en Publicidad, Relaciones Públicas y Comunicación Audiovisual. Conservatorio Profesional de Redondela (Vigo, España). 


\section{Resumen}

En el artículo, se resumen los resultados más destacables de un estudio integrado en una investigación más general sobre la música como elemento narrativo en el cine de la República de Weimar. Esta aportación se ha acotado al estudio musical de la película considerada obra maestra del expresionismo cinematográfico alemán, Das Kabinett des Doktor Caligari, de Robert Wiene (1919). El texto se adentra en el complejo estudio de la composición realizada, en este caso, por Rainer Viertlböck en 1993, para la versión íntegra restaurada y basada en la reconstrucción del coloreado del film. Metodológicamente, se opta por un estudio de caso histórico-descriptivo, analítico-cualitativo y hermenéutico. Con un minucioso análisis músico-fílmico de las escenas, se pone de manifiesto los elementos estructurales presentes, los recursos estilísticos y estéticos utilizados, las corrientes y las tendencias que emanan, así como los instrumentos empleados en la composición musical para dicho film. La música de Viertlböck, con reminiscencias del jazz y free jazz, condensa la atonalidad, donde los continuos leitmotivs identifican instrumentos con personajes, sus acciones y sentimientos, que aportan unidad musical al relato fílmico como elemento narrativo. Una composición rica en efectos (loop, riff, delay o bending) que combina instrumentos de música electrónica con viento-madera y piano. La música en el Cine de Weimar es un campo poco investigado frente a la diversidad de estudios existentes desde otras disciplinas, las aportaciones sobre la composición musical de estas películas son escasas y no se encuentran estudios músico-fílmicos de la naturaleza que se presenta en esta contribución.

Palabras claves: cine y música; cine expresionista; cine República de Weimar; Das Kabinett des Doktor Caligari; Rainer Viertlböck; corrientes musicales

\section{Abstract}

In the article are summarized the most important This article summarizes the most important results of a study integrated in one more general research on music as a narrative element in the cinema of the Weimar Republic. This contribution has been limited to the musical study of the film which is considered the masterpiece of the German cinematographic expressionism, Das Kabinett des Doktor Caligari by Robert Wiene (1919). The text penetrates into the complex study of the musical composition realised, in this case, by Rainer Viertlböck in 1993, for the restored complete version based on the colour restoration of the film. Methodologically, this is a historical-descriptive, analytical-qualitative and hermeneutical approach. Through a scrupolous musical-filmic analysis of the scenes, it shows the structural elements, the stylistic and aesthetic recurrences, the movements and the tendencies derived, as well as the instruments used in the musical composition of the above mentioned film. Viertlböck's music, with reminiscences of jazz and free jazz focuses on atonality, where the continuous leitmotivs identify instruments with characters, their actions and feelings, while bringing musical unity to the film story as a narrative element. A rich composition in effects (loop, riff, delay or bending) that combines instruments of electronic music with wind-wood and piano. Music in the Weimar Cinema is a field which has been Little researched in contrast to the diversity of existent studies from other disciplines, the contributions on the musical composition of these films are scarce and musical-filmic studies of the nature that is presented in this contribution can't be easily found.

Keywords: cinema and music; expressionist cinema; cinema of the Weimar Republic; Das Kabinett des Doktor Caligari;

Rainer Viertlböck; musical movements

\section{Resumo}

No artigo resumem-se os resultados mais destacables de um estudo integrado em uma investigação mais geral sobre a música como elemento narrativo no Cinema da República de Weimar. Esta contribuição tem-se acotado ao estudo musical do filme considerado obra-prima do expresionismo cinematográfico alemão, Das Kabinett des Doktor Caligari de Robert Wiene (1919). O texto introduze-se no complexo estudo da composição musical efectuada no presente caso por Rainer Viertlböckem 1993, para a versão íntegra restabelecida e baseada na reconstrução do colorido do filme. Metodologicamente opta-se por um estudo de caso histórico-descritivo, analíticoqualitativo e hermenêutico. Através de um minucioso análise músico-fílmico das cenas tornam-se evidentes os elementos estruturais presentes, os recursos estilísticos e estéticos utilizados, as correntes e tendências que emanan, assim como os instrumentos utilizados na composição musical para dito filme. A música de Viertlböck, com reminiscências de jazz e free jazz condensa a atonalidad, onde os contínuos leitmotivs identificam instrumentos com personagens, suas acções e sentimentos, aportam unidade musical ao relato fílmico como elemento narrativo. Uma composição rica em efeitos (loop, riff, delay ou bending) que combina instrumentos de música electrónica com vento-madeira e piano. A música no Cinema de Weimar é um campo pouco pesquisado em frente à diversidade de estudos existentes desde outras disciplinas, as contribuições sobre a composição musical destes filmes são escassas e não se encontram estudos músico-fílmicos da natureza que se apresenta nesta contribuição.analíticoqualitativo e hermenêutico. Através de um minucioso análise músico-fílmico das cenas tornam-se evidentes os elementos estruturais presentes, os recursos estilísticos e estéticos utilizados, as correntes e tendências que emanan, assim como os instrumentos utilizados na composição musical para dito filme.

Palavras chave: cinema e música; cinema expresionista; cinema República de Weimar; Das Kabinett des Doktor Caligari; Rainer Viertlböck; correntes musicais 


\section{INTRODUCCIÓN Y MARCO DE REFERENCIA}

Desde principios de la segunda década del siglo XX había constancia de algunos precedentes fílmicos expresionistas (Kracauer 1985, 35-40), como Der Student von Prag (Stellan Rye y Paul Wegener, 1913), Der Golem (Paul Wegener y Henrik Galeen, 1914), Der Andere (Max Mack, 1913) y Homunculus (Otto Rippert, 1916), pero no será hasta la producción de Das Kabinett des Doktor Caligari (Robert Wiene, 1919) cuando se puede referenciar propiamente el inicio del cine expresionista (Eisner 1996, 21-37; Mitry 1974, 38-39), en la recién instaurada República de Weimar, donde surge también la escuela de diseño Bauhaus de Walter Gropius.

El interés por el cine expresionista ha generado múltiples estudios, de matiz teórico, histórico, sociológico, psicológico, artístico-estético, semiótico (Barlow 1982; Courtade 1984; Eisner 1996; Fernández 1961; Gresch 1981; Grignaffini y Cuaresima 1978; Gombrich 1992; Gubern 1992; Hernández 1990; Kracauer 1985; Mitry 1974; Richard 1979; Sánchez-Biosca 1985, 1990), que han contribuido a enriquecerlo desde diferentes disciplinas y enfoques, pero existe todavía hoy una limitación: la carencia de aportaciones desde el ámbito musical.

Aunque existen algunas monografías, historia de la música en el cine, corrientes musicales, otras más técnicas (Beltrán 1984; Chion 1997; Colón, Infante y Lombard 1997; Gertrudix 2003; Güller 2010; Lack 1999; i Falcó 1995; Morgan 1999; H. Navarro Arriola y S. Navarro Arriola 2003; Nieto 1996; Xalabarder 2006), faltan aportaciones en torno a la banda sonora en este cine, centradas en el estudio de la composición musical y, más concretamente, en el análisis de las partituras propiamente dentro del relato fímico.

Si en todas estas contribuciones se vislumbra dicha ausencia, tal vez esto pueda estar ocasionado por circunstancias de la propia naturaleza de estas producciones (al tratarse de películas no sonoras), por la situación contextual (desaparición de muchos films como consecuencia de los periodos bélicos), por las propias características técnicas de la película (mala conservación del soporte), por la mutilación de algunas producciones sujetas a continuos montajes (lo cual ha ocasionado la aparición de fragmentos desconocidos para el espectador), por las nuevas versiones (con restauración íntegra coloreada) o simplemente por el hecho más común, pues, en el cine no sonoro, la música se interpretaba in situ con una orquesta sinfónica en la sala de cine o de teatro en el momento del estreno de la película y, en la mayoría de los casos, la partitura acababa extraviándose; y cuando se distribuía el film, este se proyectaba con acompañamientos no originales interpretados a lo sumo por un piano o cuarteto de cuerda. Estas circunstancias, en cierta manera, justificarían la omisión existente por abordar la investigación desde el ámbito musical. Teniendo presente esta laguna, resulta interesante y pertinente contemplar un estudio desde tal perspectiva, desde el punto de vista de la música como elemento narrativo en el relato fílmico.

\section{MATERIAL, MÉTODOS Y PUNTO DE PARTIDA}

La aportación se centra en la película Das Kabinett des Doktor Caligari, de Robert Wiene, de 1919 (tabla 1) y se escoge para el análisis musical la composición realizada por Rainer Viertlböck (1993). Metodológicamente, se opta por un estudio de caso (Escudero, Delfín y Gutiérrez 2008), de tipo analítico-cualitativo (Sierra Bravo 1983) y descriptivo-hermenéutico (Ashworth 2000), para un análisis estructural de la música como elemento narrativo en el film (Riemann 1928). Un estudio donde se han teniendo en cuenta aspectos melódicos, armónicos, tímbricos, motívicos, así como recursos estilístico-estéticos, que emanan de la música e imagen cinematográfica (fuente sonora, plano sonoro, funciones, etc.) y los instrumentos utilizados en la composición musical. 


\section{TABLA 1. FICHA TÉCNICO-ARTÍSTICA-CONTENIDOS-CONTEXTO DE LA PELÍCULA}

\begin{tabular}{|c|c|c|c|}
\hline Título V.O. & Das kabinett des Doktor Caligari & Año producción & 1919 \\
\hline Producción & \multicolumn{2}{|l|}{ Erich Pommer, Rudolf Meinert } & Productora \\
\hline Distribución & \multicolumn{2}{|l|}{ DVD. Divisa Home Video 2008} & Restauración \\
\hline Director & Robert Wiene & Guión & $\begin{array}{l}\text { Carl Mayer, } \\
\text { Hans Janowitz }\end{array}$ \\
\hline Fotografía & \multicolumn{2}{|l|}{ Willy Hameister } & Dirección artística \\
\hline Reparto & \multicolumn{3}{|c|}{ Werner Kraus (Dr.Caligari), Conrad Veidt (sonámbulo Cesare), Friedrich Feher (Francis), Lil Dagover (Jane), } \\
\hline Argumento & \multicolumn{3}{|c|}{ La idea está basada en un suceso real de criminalidad sexual en Hamburgo publicado en prensa y en } \\
\hline Sinopsis & \multicolumn{3}{|c|}{$\begin{array}{l}\text { Dos amigos (Francis y Alan) enamorados de Jane acuden a la feria de Holstewall, donde un enigmático } \\
\text { ocurre la predicción, Francis decide investigar con la ayuda del padre de Jane, que es secuestrada por } \\
\text { mete asesinatos. Cesare es atrapado y Jane liberada. Mientras Caligari huye y se refugia en un manico- }\end{array}$} \\
\hline Guión & \multicolumn{3}{|c|}{$\begin{array}{l}\text { El guion original se modificó añadiendo } 2 \text { escenas (introducción y epílogo) que cambiaron el sentido de la } \\
\text { tanto Fritz Lang (iba ser el director al principio) como Robert Wiene, con la oposición de los guionistas. } \\
\qquad \text { Inicio-Presentación: corresponde a la parte introductoria añadida al guion original. La escena aborda } \\
\text { Desarrollo-Nudo: corresponde al guion original escrito por Janowitz y Mayer. Comienza cuando Fran- } \\
\text { flash-back (Duración: 4'01"- } 1 \mathrm{~h} .08^{\prime} 03^{\prime \prime} \text { ) } \\
\text { Desenlace-Epílogo: coincide de nuevo con la escena de la conversación en el jardín entre Francis y el } \\
\text { ción de sonambulismo, observado por el director/doctor Caligari (Duración: } 1 \mathrm{~h} .08^{\prime} 04^{\prime \prime}-1 \mathrm{~h} .13^{\prime} 16^{\prime \prime} \text { ). }\end{array}$} \\
\hline Contexto & \multicolumn{2}{|l|}{ Histórico (tras la la Guerra Mundial) } & Político (República de Weimar) \\
\hline $\begin{array}{l}\text { Influencias } \\
\text { culturales }\end{array}$ & \multicolumn{2}{|l|}{ Romanticismo alemán } & Literatura (corriente fantástica) \\
\hline Decorados & \multicolumn{3}{|c|}{ Janowitz sugirió para su diseño a Alfred Kubin pero, Wiene prefirió a tres artistas expresionistas (Hermann } \\
\hline lluminación & \multicolumn{3}{|c|}{$\begin{array}{l}\text { Estilo expresionista. Intensa luz principal (fuerte) combinada con baja luz (relleno). Los decorados se ilu- } \\
\text { sombras), dando un mayor toque de irrealidad. }\end{array}$} \\
\hline Restaurado & \multicolumn{3}{|c|}{$\begin{array}{l}\text { Se estrenó con copias coloreadas con diversos tintes para las diferentes secuencias y tras la premier sólo } \\
\text { original (1984) se hizo de dos copias, en diferente estado de conservación, procedentes de Londres y } \\
\text { Con la copia completa en B/N se restauró los colores originales en su tonalidad exacta (sirviéndose de } \\
\text { Kinemathek (se recuperaron los diseños originales de los rótulos en alemán). }\end{array}$} \\
\hline
\end{tabular}




\begin{tabular}{l|l|l|l|l|}
\hline Alemania & Estreno & Berlín, 26 de febrero de 1920 & Duración & $74^{\prime}$ \\
\hline Decla Film-Gesellschaft Berlin & Género & Fantástico-Terrorífico \\
\hline
\end{tabular}

Versión íntegra (Friedrich Wilhelm Murnau Stiftung)

Giuseppe Becce (la partitura);

Rainer Viertelböck (composición musical 1993)

\begin{tabular}{l|l|l}
\hline Hermann Warm, Walter Reimann, Walter Röhrig & Diseño vestuario & Walter Reimann \\
\hline
\end{tabular}

Hans Heinrich von Twardowski (Alan), Rudolf Lettinger (Dr. Olson), Rudolf Klein-Rogge (falso criminal).

un espectáculo de hipnosis en una feria ambulante.

doctor (Caligari) exhibe como atracción un sonámbulo (Cesare) que anticipa el futuro y pronostica la muerte de Alan. Cuando Cesare. Comienza la persecución y descubren que Cesare (bajo hipnosis del Dr. Caligari) atiende sus peticiones malignas y comio pero Francis descubre horrorizado que el director del centro y el doctor son la misma persona.

historia, por lo que el cuento de terror se convirtió en el relato de alucinación de un loco. Esta modificación la sugirió a Pommer, la conversación de Francis en el jardín del manicomio con un paciente. (Duración: 02'10"- 4').

cis recuerda cómo conoció a Caligari y al sonámbulo Cesare y cuenta su historia al paciente. Se recurre a la técnica narrativa del paciente (parte final añadida al guion original). La escena contempla a los personajes del film en el patio del manicomio en situa-

Cultural Escuela Bauhaus (W. Gropius)

Kammerspiel (M. Reinhard)
Cinematográfico (1919-1924)

Psicoanálisis (S. Freud)
Arte (Primeras vanguardias)

Warm, Walter Röhrig y Walter Reimann), vinculados al grupo Sturm de Berlín, para los decorados pintados en tela.

minan en la base (marcar el relieve deformado), disponiendo de grandes proyectores a los lados del decorado (acentúa luces y

se conservaron copias en B/N y, algunas, con el metraje original reducido. La primera restauración para devolverle el tintado Montevideo. Luego se localizaron 3 copias con los tintados originales, que sirvieron para la restauración de la edición analizada. catálogos Agfa de los años 20 conservados por un coleccionista) y con una copia en $16 \mathrm{~mm}$ propiedad de la Stiftung Deustche 
Los motivos de esta elección — de film y compositor- están en que esta película es considerada la obra maestra del expresionismo que abre el periodo del cine de la República de Weimar (Sánchez Biosca 1985, 45 y ss.), que dentro de poco celebrará su centenario. Con respecto a la selección del compositor, se ha de indicar que su creación musical fue compuesta exclusivamente para la única versión íntegra restaurada del film (metraje completo y diseños primitivos de los rótulos en alemán), realizada por la Friedrich Wilhelm Murnau Stiftung y basada en la reconstrucción del coloreado original (tintados y virados) de la película a cargo del Bundesarchiv film archive (Berlín). ${ }^{1}$ Además, se trata de una contribución científica inédita en el ámbito, pues no se hallan estudios específicos al respecto.

Aunque el expresionismo tiene una influencia significativa en esta película, este movimiento surge mucho antes de la Primera Guerra Mundial y tendrá su vigencia en el ámbito cinematográfico después del conflicto bélico (Murphy 1999, 4-5; Willett 1970, 7). El cataclismo de la guerra y sus consecuencias influyen en el pueblo alemán y, en ese contexto de la República de Weimar, emergen nuevas corrientes culturales como instrumentos revolucionarios contra el sistema y frente al realismo naturalista. Las influencias del film se encuentran en el romanticismo alemán, concretamente en el movimiento Sturm und Drang (Reale y Antiseri 1988, 29-30) que hace hincapié en la libertad del individuo, la exaltación del sentimiento patriótico a través del odio a la figura del tirano y el deseo de vulnerar las convenciones establecidas. Aunque también la literatura, corriente fantástica y novela gótica, contribuyen temáticamente a su gestación (confluencia de dos mundos antagónicos, el real y el del subconsciente, ambientación tenebrosa, etc.), así como el teatro, con las contribuciones de Max Reinhardt (Kammerspie) que se hicieron notar en la puesta en escena (fusión de personajes y decorados en un todo), al igual que el contexto histórico germánico de esos años se ve referenciado en el film (Kracauer 1985, 73), como una premonición de lo que estaba aún por acontecer en la Alemania de entreguerras.

Sin embargo, cuando la película se estrena (Berlín, 26 de febrero de 1920), no se recurre a música expresionista que sería lo esperado, sino a música de compositores clásicos y románticos, como Beethoven, Schubert, Rossini, Bellini y Donizetti (Navarro Arriola 2005, 53), no siendo esta bien aceptada por la crítica y el público asistente. Y como la música de acompañamiento tiene importancia determinante en el éxito o fracaso de una película (Berriatúa 1990, 385), el productor de la UFA (Universum Film AG), Erich Pommer, recurre al italiano Giuseppe Becce para crear una composición específica para la película, cuya partitura desapareció. Becce, quien había compuesto previamente para cine (Rancan 2012) la película alemana Richard Wagner (Carl Froelich y William Wauer, 1913) y para Robert Wiene (Frau Eva, Die Räuberbraut, Der Liebesbrief der Königin, Der Mann im Spiegel, etc.), tuvo la capacidad de recopilar repertorios y sistematizar con ello una serie de indicaciones musicales orientativas para el acompañamiento de películas no sonoras, donde reunía formas de describir momentos emotivos de las escenas (tensión, drama, amor, etc.). Esta colección la publicó (Konigsberg 2004, 346) bajo el título abreviado de Kinothek (Kinobibliothek, 1919). Tiempo después, en colaboración con el compositor Hans Erdmann, publicaba un nuevo decálogo más amplio y detallado, Allgemeines Handbuch der Film-Musik (1927).

Ha habido intentos de reconstruir lo que podría haber sido aquella composición original realizada por Becce, realizándose varias versiones con diferentes estilos musicales (Alfredo Antonini, Timothy Brock, Richard Marriott, Peter Schirmann, Rainer Viertlböck, etc.) y alguna a partir de documentos del propio Becce, siendo la aproximación más fiel de su composición. 
Se trata de una partitura para once instrumentos (violín, violonchelo, contrabajo, flauta, oboe, clarinete, trompeta, trombón, piano, órgano y percusión) y en ella predomina un tono sombrío entremezclado con motivos intimistas y melancólicos (Navarro Arriola 2005, 54).

Ahora bien, el estudio de la partitura de Viertlböck es de gran interés en el ámbito de la musicología, tanto por las posibilidades que ofrece su propuesta creativa como por componer una obra musical completa para la única versión íntegra restaurada del film existente.

\section{RESULTADOS}

\section{COMPOSICIÓN MUSICAL DE VIERTLBÖCK PARA CALIGARI}

En la película objeto de estudio, Das Kabinett des Doktor Caligari, en la versión realizada e interpretada por Rainer Viertlböck, se observa que su partitura responde a un estilo musical correspondiente al jazz y, al decantarse por este, se aleja de las anteriores composiciones realizadas, siendo algunas de ellas más clásicas. A modo sucinto, una de las grandes cualidades de la música jazz (Berendt 1993; Francis 1972; Goffin 1958; Panassié 1961; Tirro 2001) tiene que ver con el logro de una sonoridad distintiva e innata que les identifique ante otros creadores (Berendt 1993, 226228). En su filosofía de creación, no persiguen la búsqueda de la pureza en sí misma, sino más bien el logro de conseguir mayor expresividad con el instrumento, por lo que se podría manifestar que en el jazz la expresión prevalece sobre la estética. Se trata de una música esencialmente improvisada, donde los músicos parten de una serie de esquemas previos que repentizan sobre la estructura armónica de los motivos. La evolución es una constante en todo el proceso creativo y la búsqueda de nuevas sonoridades convive con la introducción de ignotos elementos dentro de las creaciones musicales. Cuando el compositor aplica esta conceptualización es para reforzar acciones o más bien descubrir otros niveles sonoros, desde notas sutiles a otras más evidentes, al igual que un pintor resaltaría las pinceladas de los grandes trazos del lienzo o un director cinematográfico convertiría la toma en un prolongado plano-secuencia con el discurrir de diferentes encuadres, movimientos y angulaciones en el fluir de la cámara por la escena.

Lo realmente novedoso de la composición musical de Viertlböck es su instrumentación basada en sintetizador, guitarra eléctrica, saxofón alto, teclado, bajo eléctrico, piano y batería. Se trata, por tanto, de una banda sonora moderna, pues, a partir de la década de 1970 evoluciona la música electrónica y sintética, con reminiscencias del free jazz por su gran cantidad de cromatismos llevada en ocasiones hasta la atonalidad. No se puede olvidar que este estilo musical surge del mismo modo que el atonalismo, como consecuencia lógica de la evolución y de las formas establecidas. Así lo contemplaba Berendt cuando afirmaba que "el jazz posee una tradición de atonalidad (o despreocupación armónica), creada básicamente por la vanguardia clásica que empezó con Schönberg, Webern y Berg" $(1993,58)$. Los compositores de la Escuela de Viena vinculados a la estética expresionista emplearon el atonalismo, aunque el propio Arnold Schönberg no se reconocía expresionista ni tampoco atonalista (Pombo 2001, 224).

Es evidente que las corrientes musicales precedentes y, más concretamente, la herencia de Richard Wagner, su música, aunque es básicamente diatónica, está tan llena de cromatismos que llegaron a eliminar el concepto de centro tonal (Sadie 1995, 355), o Gustav Mahler, con las disonancias agrestes que superan los límites de la tonalidad (Alsina y Sesé 1997, 86), prepararon el camino para todos aquellos que, en los primeros años del siglo XX, rompieron con el sistema tonal. 
El intenso empleo del cromatismo, unido a la tensión expresiva a menudo teñida de pesimismo, caracteriza la música expresionista que alcanzó su apogeo en el periodo de entreguerras (Morgan 1999). Las composiciones emocionalmente intensas (como expresión de las ansiedades personales y de los terrores ocultos) deforman las técnicas convencionales y reemplazan las armonías tradicionales por otras disonantes. La música, a menudo, es atonal o producto de la distorsión, la polifonía (esa simultaneidad de líneas melódicas) es, con frecuencia, densa y pesada y la melodía prácticamente irreconocible.

En esta versión musical de Das Kabinett des Doktor Caligari, Viertlböck compone la misma melodía para la apertura de inicio de la película y el cierre del final. Una misteriosa y desconcertante melodía de sintetizador para evocar siempre la misma idea en el espectador (la incertidumbre), con esa sensación de lejanía (marcando la soledad del ser) que, poco a poco, se va perdiendo al disminuir en intensidad (referenciando la ausencia) y a medida que la imagen desaparece totalmente al fundirse a negro (resaltando la nada). A lo largo de la película, se Ilenan los espacios sin música solo con el sintetizador (recalcar la sensación no real de silencio), empleando los demás instrumentos (agitación de elementos musicales para recrear un ambiente caótico) cuando en escena sucede algo importante o la acción así lo requiere. Una melodía de jazz distorsionada es un recurso empleado de forma recurrente para aquellos momentos en que brota una inhóspita violencia (manifiesta o larvada) en la escena (el asesinato de Alan en su habitación o el secuestro de Jane, etc.).

Aunque se trata de una música esencialmente improvisada, se puede apreciar la influencia del leitmotiv wagneriano. Esta estrategia en la creación de la composición musical la apuntaba Michel Chion: “El 90 \% de las partituras de películas de la época clásica y moderna están constituidas sobre leitmotiv, dando como resultado varios centenares de partituras que presentarían similitudes con Wagner" (1997, 259). De este modo, cada vez que aparece uno de los personajes principales - Caligari, Cesare, Francis o Jane — la instrumentación cambia. Esta forma de proceder está muy presente en la producción fílmica, y así lo ponía de manifiesto también el compositor Erno Rapee que creaba para cada personaje principal del relato un tema musical, al igual que lo hacía para el escenario en su integridad (Hall 1987, 176).

En su creación, Viertlböck apuesta por que la música se relacione simbióticamente con todos y cada uno de los elementos que fluyen en la imagen de cada escena. De este modo, describe con notas musicales los estados psíquicos inestables de los personajes (su trastorno mental), la crisis de identidad del contexto (personal y social), la conexión con un paisaje urbano distorsionado arquitectónicamente (escenografía difícil de concebir en la realidad porque forma parte del mundo onírico), la densa atmósfera de pesadilla (recrear el subconsciente escondido en las entrañas del ser) y esa sociedad enfermiza (la Alemania de entreguerras mundiales) sumergida en una nauseabunda descomposición (social, política y moral).

La partitura de Viertlböck a veces ofrece dos planos sonoros distintos al mismo tiempo: uno, irreal, basado en la música electrónica, sintética, heredera de la tradición musical de la década de 1970 que experimenta con sintetizadores; y el otro, real, con instrumentos de percusión. Ambos planos suelen fundirse para crear sonoramente un ambiente claustrofóbico y de inestabilidad emocional (representaría el mundo del lado oscuro de la mente). Y en esos diferentes planos, la mezcla de sonidos llega a fusionarse con las onomatopeyas (puertas que se abren o se cierran, crujir de maderas, etc.) que crea una sensación sonora caótica (mostrar el mundo interior de los personajes y las situaciones de las que son prisioneros) y que se traduce en un desorbitado ambiente sonoro. Otras veces, su composición deja asomar instrumentos 
de viento con los de cuerda e irrumpe el saxofón alto y el piano para protagonizar una escena íntima y de dolor. Los instrumentos se identifican con los sentimientos de los personajes, así el piano distorsiona aún más las emociones con sus acordes repetitivos y lineales (matizando la atmósfera obsesiva que respira el film), mientras el saxo alto agudiza sus notas, hirientes, largas y chirriantes (como cuchillos que se clavan en el oído del espectador a modo de metáfora de locura). Los sentimientos que emana la imagen cinematográfica, Rainer los plasma en unas notas musicales muy acordes con la estética del cine de la República de Weimar, pero en un contexto creador de principios de década de 1990.

\section{ESTUDIO MÚSICO-FÍLMICO DE CALIGARI}

En esta contribución, por razones de espacio, se ha seleccionado, para el minucioso análisis músico-fílmico de la partitura de Rainer Viertlböck, tres secuencias emblemáticas de la película, consideradas por los historiadores Kracauer $(1985,63-77)$ y Sánchez-Biosca $(1985,65-72)$ de gran relevancia significativa dentro de la estructura narrativa del film. Los tres fragmentos están integrados dentro del film en la parte correspondiente a lo que fue en un principio la versión original de guion (Eisner 1996, 22; Kracauer 1985, 67-68) creado por Hans Janowitz y Carl Mayer —ambos manifestaron siempre su desacuerdo a la modificación realizada por el director Robert Wiene y sugerida previamente por Fritz Lang al productor Erich Pommer- y que tras el cambio efectuado corresponde a la parte del desarrollo-nudo y se estructura narrativamente en torno a la técnica de flash back. Pero se ha hecho énfasis en su elección por tratarse de tres fragmentos fílmicos completamente diversos musicalmente, lo cual permite realizar un estudio integral, más profundo y detallado de la banda sonora de Das Kabinett des Doktor Caligari.

Así, la primera secuencia corresponde a la Feria de Holstenwall (duración: 9 min 53 s-12 min 28s ); la segunda, es la del Secuestro de Jane (43 min $2 \mathrm{~s}-47$ min 14 s); y la tercera, Tengo que ser/convertirme en Caligari (1 h 1 min 19 s-1 h 3 min 21 s). En el estudio, se ha analizado a fondo elementos estructurales (melódicos, armónicos, tímbricos, motívicos) y recursos estilístico-estéticos que emanan de la música e imagen cinematográfica (fuente sonora, plano sonoro, funciones, etc.) y los instrumentos utilizados en la composición musical.

\section{ANÁLISIS ESTRUCTURAL DE LAS SECUENCIAS}

La escena más significativa, no solo desde el punto de vista de la imagen, sino también de la banda sonora, es la de la Feria de Holstenwall (9 min 53 s-12 min 28 s). Por vez primera aparece la feria (uno de los lugares centrales donde se desarrolla la acción) y se presentan los personajes (doctor Caligari, sonámbulo Cesare, amigo Alan). Un recorrido por la imagen nos lleva a un paisaje donde todos los elementos urbanos y personajes se fusionan y configuran un entorno caótico, una composición espacial compleja por los distintos elementos visuales que se entrecruzan para reforzar el encuadre. Por un lado, la direccionalidad horizontal (que resalta el espacio central donde se mueven los personajes), remarcada por la diagonal visualmente manifiesta (representada en el pasamanos de la escalera) que evita cualquier punto de fuga y que irrumpe para unir el devenir giratorio de las atracciones (dos calesitas, una en la esquina superior derecha, y otra, en esquina inferior izquierda) frente al estatismo del paisaje de fondo (una montaña de edificios a modo de torre de Babel). Un paisaje de fauna humana diversa que engloba al mundo entero en una feria (el arquetipo del burgués en la figura de Caligari, 
el organillero, el enano, las chicas, los diversos feriantes). Esta imagen de paisaje cerrado y estático (toma frontal, encuadre general sin movimientos de cámara) alberga en sí misma mucho dinamismo, tanto en los continuos andares de sus personajes (campo in/out) como en el motivo rítmico de la música (incesantemente repetitiva) y del organillero, cuyo brazo gira y gira a la vez que las atracciones de feria (que recuerda el caos de un remolino) para recrear un ambiente confuso que se refuerza con la banda sonora (tabla 2).

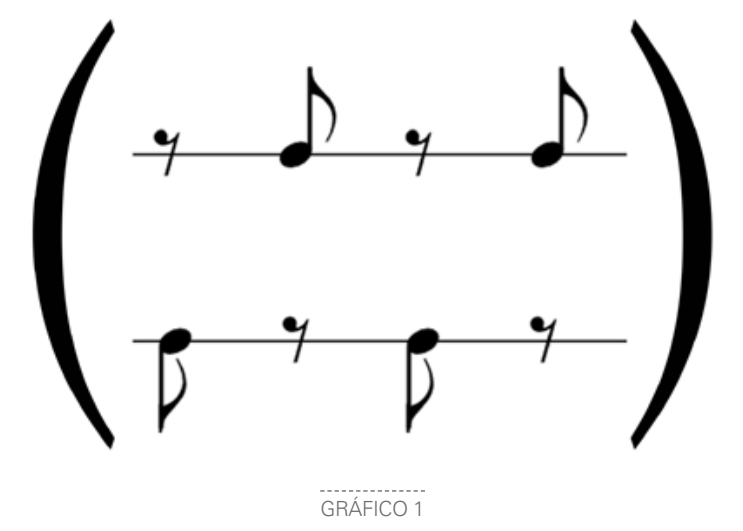

Rainer Viertlböck apuesta musicalmente en la escena presentando un esquema rítmico que actúa como motor y refleja el constante movimiento de la feria (calesitas, organillero). A este elemento generador, se superponen melodías que nos recuerdan patrones con un tratamiento especial de los acentos (gráfico 1).

Los instrumentos que intervienen son el piano, el saxofón alto, el sintetizador y los tambores. Desde el punto de vista musical, se trata de una composición monotemática sobre un desarrollo de una secuencia acórdica, con un bajo móvil desde que parte la fundamental del acorde que juega con los intervalos propios de este. Encima de esta base armónico-rítmica, a modo de contracanto, se introduce el saxofón alto, que suena como contraposición melódica a la idea del piano, que mantiene siempre su ostinato rítmico-melódico de fondo.

Comienzan solo el piano y los tambores de fondo. El ritmo simula el movimiento frenético de las calesitas (que siempre que aparecen en escena utilizan el mismo motivo musical) y la entrada y salida constante de personajes de la escena. Se describe el ambiente de la feria por medio de una música agobiante y constante. El saxofón hace su entrada con tan solo una nota, para terminar de aparecer más tarde repitiendo el mismo motivo de escala descendente. Este instrumento da un tinte misterioso a la composición, y aunque la base rítmica se mantiene, la melodía del piano cambia. Y este cambio coincide con la entrada en escena de Caligari que, con un ritmo cadencioso y lento, se detiene en el centro del plano (marca su presencia como personaje principal del relato) y se mofa de un enano. En este instante, el piano se mueve por los registros graves y crea sensación de desasosiego y ansiedad.

El acompañamiento que en un principio se muestra en primer plano como material temático principal nos recuerda a un loop sobre el que se superponen melodías con reminiscencias al free jazz, aunque con conexión entre el piano, el saxo y el sintetizador. Esta especie de loops da interés a melodías poco depuradas, breves, que el compositor usa en favor de la escena. Pasajes diatónicos descendentes que nos llevan a la altura principal. La acción de mezclar sintetizador con piano nos adentra en un mundo oscuro, que resalta lo que requiere la imagen: generar tensión en el espectador.

XX' Cuadernos de Música, Artes Visuales y Artes Escénicas / Volumen 12 - Número 2 julio - diciembre de 2017 / ISSN 1794-6670/ Bogotá, D.C., Colombia / pp. xx 
Tabla 2. Ficha musical de la secuencia $<<$ La feria $>$

\begin{tabular}{|c|c|}
\hline SECUENCIA & La feria \\
\hline Minutado & $09^{\prime} 53^{\prime \prime}-12^{\prime} 28^{\prime \prime}$ \\
\hline \multicolumn{2}{|l|}{ Fotograma } \\
\hline \multicolumn{2}{|l|}{$\begin{array}{l}\text { Análisis musical } \\
\text { (Gráfico } 1 \text { y } 2 \text { ) }\end{array}$} \\
\hline Instrumentos & Piano, saxofón alto, sintetizador y tambores \\
\hline $\begin{array}{l}\text { Características de } \\
\text { la composición }\end{array}$ & Reminiscencias al free jazz, loops, melodías improvisadas \\
\hline Desarrollo musical & $\begin{array}{l}\text { Composición monotemática sobre secuencia acórdica + bajo rítmico, } \\
\text { ostinato rítmico-melódico de piano, escala descendente saxofón }\end{array}$ \\
\hline \multicolumn{2}{|l|}{ Fotograma } \\
\hline $\begin{array}{l}\text { Análisis musical } \\
\text { (Gráfico 3) }\end{array}$ & $\vec{\square}$ \\
\hline Instrumentos & Piano, saxofón alto, sintetizador y tambores \\
\hline Desarrollo musical & $\begin{array}{l}\text { Tremolo piano, ostinato rítmico tambores, progresión ascendente de } \\
\text { piano, sintetizador como colchón armónico }\end{array}$ \\
\hline
\end{tabular}

Elaboración propia, 2015 
El elemento compositivo, además del citado elemento rítmico generador inicial, está basado en ictus motívicos muy breves, que posteriormente son desarrollados imitando a improvisaciones. De vital importancia son los reguladores (crescendo, decrescendo) que acompañan las melodías durante toda la secuencia y ayudan a reflejar esa sensación de vertiginoso agobio. Con el tratamiento de las dinámicas, se busca apoyar los rasgos propios de la música electrónica y así dar cobertura al conjunto. A continuación, pasa a escucharse el sonido de un yunque, de un metal afinado golpeado rítmicamente (representa al enano). El piano repite un ostinato que refuerza el ambiente crispante y que siempre resuelve en el mismo acorde acentuado (gráfico 2).

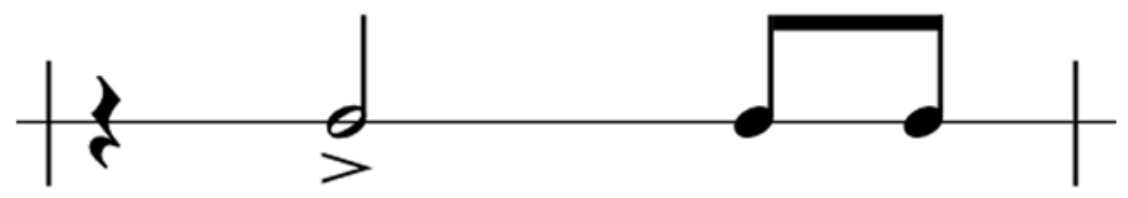

GRÁFICO 2

Más tarde, vuelve a hacer su aparición el saxofón con la misma escala descendente anterior y la música se mantiene constante (cuando sale de su tienda de la feria). Es entonces cuando mueve la campana que lleva en la mano a fin de llamar la atención de los feriantes para comunicarles que el espectáculo (de mostrar un sonámbulo) va a comenzar, sonando un trémolo de piano en el registro agudo que simboliza el sonido de la propia campana. Se escuchan de fondo tambores, y cuando el doctor abre la tela para mostrar el dibujo de Cesare, la música de piano adquiere una progresión ascendente. Y es más adelante, cuando se comienza a escuchar el sintetizador que crea un colchón armónico, que coincide con la aparición del intertítulo "Pasen y vean. Por primera vez en la feria... iCesare el sonámbulo!".

El empleo de sonidos largos sobre sintetizador y percusión apoya los picos sonoros que sirven para respaldar la acción de la secuencia. Se pueden definir elementos propios de la música para momentos concretos (gráfico 3).

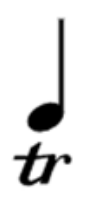

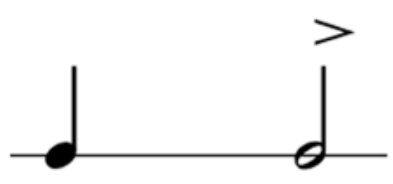

GRÁFICO 3

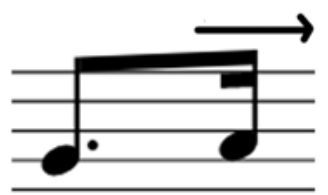

\section{Cromatismo}


Poco después se retoma la melodía de piano inicial con el sintetizador de fondo que da por terminada la primera secuencia. El papel del doctor Caligari se representa en esta escena por medio del piano. Este personaje, por su vestuario (capa, chistera, gafas, levita, botines, bastón, guantes) de estilo Biedermeir (influencia del naturalismo aburguesado), connota ser un respetable profesional (doctor) y una persona distante (para las clases más bajas socialmente); y como el piano, que en sus inicios fue un instrumento que se atribuía a la burguesía y a la aristocracia, al estar tocado en el registro grave, da la sensación de oscuridad y de misterio (para remarcar la personalidad enigmática del personaje Caligari).

En referencia a la segunda secuencia, Secuestro de Jane (duración: 43 min 2 s- 47 min $14 \mathrm{~s})$, tal vez se trate del fragmento más sentimental, al más puro estilo del romanticismo en cuanto a su contenido: el sonámbulo Cesare tiene encomendado (a través del proceso de hipnosis del doctor Caligari) matar a Jane, pero no la asesina (se siente atraído por ella) y acaba raptándola (amor no correspondido). Huye con ella por un desolado paisaje y deja a su padre y a Francis desconsolados por su pérdida.

La composición visual de la escena escenifica simbólicamente la metáfora del bien y del mal (Jane duerme plácidamente y Cesare irrumpe en su habitación y por desamor la secuestra) y combina dualmente cada uno de los distintos elementos presentes en la puesta en escena: desde los personajes (la fealdad representada en Cesare frente a la belleza de Jane) hasta el color de su vestimenta (el blanco camisón de Jane frente al maillot negro de Cesare), el juego de iluminación (la oscuridad de fondo es la sombra del cuerpo de Cesare frente a la claridad del rostro de Jane), los elementos del atrezo (un enorme cuchillo puntiagudo en la mano de Cesare como representación fantasmal del falo, a punto de penetrar en las blanquecinas sábanas de la cama ovalada de Jane), la selección de encuadres desde el plano conjunto al detalle (intrusión de Cesare por la ventana del cuarto, su avance sigiloso hasta la cama, el gesto plácido de Jane durmiendo, el sobresalto en su rostro y forcejeo con las manos), la ambientación misteriosa (una atmósfera de incertitud, cada vez más densa y asfixiante, incrementa la angustia del espectador que se acentúa con el grito de Jane) y la variada composición musical de la escena (tabla 3) creada por Viertlböck.

Los instrumentos presentes son sintetizador, piano, saxofón, guitarra eléctrica y batería. En el aspecto musical, la escena comienza con un colchón de sonido sintetizado, en el que priman las oscilaciones dentro del propio sonido que dan paso a una sucesión de repeticiones (gráfico 4).

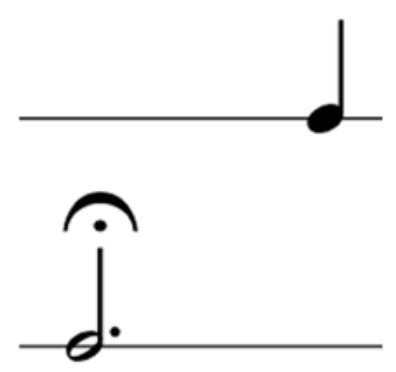

GRÁFICO 4 
Tabla 3. Ficha musical de la secuencia $<<$ Secuestro de Jane $>$

\begin{tabular}{|c|c|}
\hline SECUENCIA & 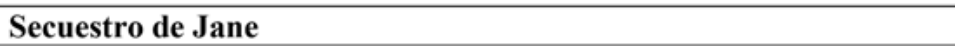 \\
\hline Minutado & 43 '02'’-47' 14'” \\
\hline \multicolumn{2}{|l|}{ Fotograma } \\
\hline $\begin{array}{l}\text { Análisis musical } \\
\text { (Gráfico } 4 \text { y } 5 \text { ) }\end{array}$ & $s f z$ \\
\hline Instrumentos & Piano, saxofón alto, sintetizador, guitarra eléctrica y batería \\
\hline $\begin{array}{l}\text { Características de } \\
\text { la composición }\end{array}$ & Reminiscencias al free jazz, loops, melodías improvisadas \\
\hline Desarrollo musical & $\begin{array}{l}\text { Ostinato sintetizador, acorde Sol menor incluyendo tensiones, } \\
\text { aceleración ritmo, riff, sforzando continuo, melodías corte improvisado, } \\
\text { líneas melódicas ascendentes, delays }\end{array}$ \\
\hline \multicolumn{2}{|l|}{ Fotograma } \\
\hline \multicolumn{2}{|l|}{$\begin{array}{l}\text { Análisis musical } \\
\text { (Gráfico } 6 \text { y } 7 \text { ) }\end{array}$} \\
\hline Instrumentos & Piano, saxofón alto, sintetizador, guitarra eléctrica y batería \\
\hline Desarrollo musical & $\begin{array}{l}\text { Loops, diálogos guitarra y saxofón, motor rítmico semicorcheas, } \\
\text { melodías improvisadas }\end{array}$ \\
\hline
\end{tabular}

Elaboración propia, 2015 
Se trata de un motor rítmico en forte, contrastado en piano con la aparición del primer armónico (3. ${ }^{a}$ menor) y apoyado por percusión sintetizada que imita el sonido de un yunque, como si se tratase de una campana de iglesia que toca a muertos o del sonido de la medianoche, frío y mecánico de la muerte (encarnada en Cesare), para simbolizar los pasos del sonámbulo que se acerca (recreando la incertitud y el miedo); en cierta manera, es un sonido parecido a los golpes con los grilletes que hacen los condenados (el sonámbulo Cesare es un preso de la voluntad del doctor Caligari). La repetición de este esquema en loop se fusiona con sonidos sintetizados y de percusión para desembocar en un nuevo colchón en valores largos.

Se emplea el acorde de sol menor en el piano por su carácter oscuro, el cual, al irle añadiendo tensiones, crea suspense. El sonido metálico en contraste con el fuerte acorde de piano parece imitar un efecto de eco (sugiere el sonido de una gota de agua al caer sobre una chapa metálica). Además, por medio de la repetición, la tensión va in crescendo (Cesare se acerca a la cama de Jane) y a medida que se aproxima se produce una aceleración en la sucesión de acordes. Este motivo rítmico melódico se mantiene (Cesare se queda perplejo admirando su belleza), y el sintetizador, que ya estaba presente en forma de colchón armónico, invade la escena por medio de un acorde fúnebre.

Este sonido representa el silencio de la noche (la habitación de Jane) y la mente en blanco del sonámbulo (Cesare). Ayuda a crear suspense, porque no se sabe si finalmente le hará daño y a medida que se acerca a ella sube el nivel sonoro (que recalca el estado de ansiedad de Cesare que empuña el cuchillo afilado). Esta imagen se refuerza musicalmente con efectos de sforzando, con sonidos en los que prima la mezcla de timbres agudos, para reforzar el movimiento de la acción (gráfico 5). En ese momento, es cuando Cesare decide tocarla, y reflejando el miedo de ella al despertarse y encontrarlo en su habitación, suena un riff triunfal con carácter apoteósico instrumentado con poliacordes. Se entremezclan homofonías direccionales con desarrollos improvisados de elementos libres.

\section{s \\ Sforzando}

GRÁFICO 5 
La velocidad de los hechos se resalta con el empleo de semicorcheas a las que se superponen melodías de corte improvisado, con sonidos de guitarra eléctrica, piano y percusión que en un crescendo gradual de la dinámica y la dirección melódica que camina hacia los agudos (nos acercan a la recuperación de Jane). Se trata de motivos repetitivos sin aparente sentido. De este modo, se crea un nuevo elemento rítmico-melódico que conduce a la explicación de lo que en escena está sucediendo. Con los crescendos y las líneas melódicas ascendentes, se unen temas en la guitarra eléctrica, con distorsión y delays (para representar la imagen por excelencia del expresionismo, el grito de terror de Jane) que, con dos voces sobreacompañamiento de teclados, son el motor que crea tensión y conduce hacia el final de la escena (gráfico 6). En este fragmento fílmico (Cesare coge a Jane por el cuello y esta grita), está presente también el saxofón que toca una nota tenida en fortísimo que acentúa la tensión del momento (el pavor de Jane).

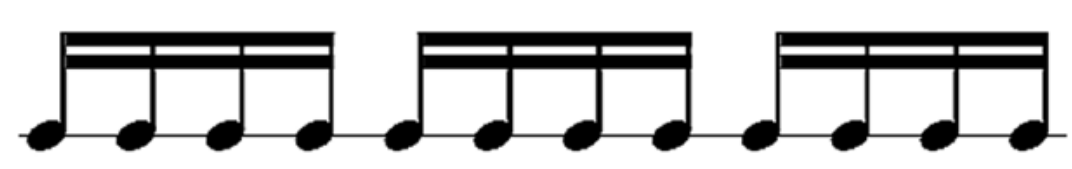

GRÁFICO 6

El movimiento interno de cada secuencia está representado por diálogos entre saxofón alto, guitarra eléctrica, percusión y loops. El piano genera acordes atonales y la batería no sigue un ritmo definido con lo cual crea un ambiente de caos. Esto tiene que ver con la aparición de más personajes en escena (el padre de Jane y Francis), ritmos con figuración breve y movimiento rápido. Se vuelve a escuchar el sintetizador (remarcando la sensación de pánico, no saber qué está sucediendo en la habitación de Jane) y se incorpora el piano, la batería y el saxofón con improvisaciones libres (amenizan el momento en que los familiares se despiertan sobresaltados por los gritos de Jane). Comienza una melodía acelerada de piano (como si se tratase de una música de persecución) cada vez más rápida, y si a esto se suma la intervención del saxofón que toca en el registro agudo, percibimos la crispación del ambiente (la exasperación de los familiares al ver que Jane no está); este motivo finaliza por medio de un break de batería (cuando el padre de Jane desolado cae rendido sobre su cama).

A continuación, la guitarra comienza con una escala ascendente y se le suma el saxofón, la percusión sintetizada y el piano (que remarcan la idea de caos, desorden y desorientación de la situación), donde la guitarra y el saxofón con su diálogo nos relatan la historia por medio de sus notas. Más tarde, se vuelve a quedar solo el sintetizador (que subraya la soledad de Francis que vigila el aposento de Caligari mientras duerme).

Un conjunto de instrumentos (saxofón, guitarra, piano y batería) con sus motivos frenéticos están presentes en el momento de la persecución del sonámbulo (Cesare escapa con Jane en sus brazos). El momento de la huida se define con melodías a modo de diálogos improvisados, combinadas con el siguiente ostinato (gráfico 7).

XX' Cuadernos de Música, Artes Visuales y Artes Escénicas / Volumen 12 - Número 2 julio - diciembre de 2017 / ISSN 1794-6670/ Bogotá, D.C., Colombia / pp. xx 


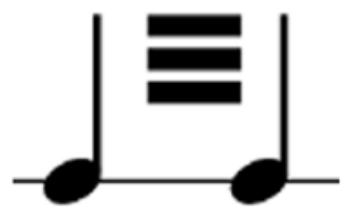

GRAFICO 7

A continuación (en imagen un exhausto Cesare abandona a Jane en su huida), se percibe que el ritmo disminuye en velocidad hasta que la música desaparece en ritardando (imitando los movimientos lentos de Cesare, cuando su cuerpo se tambalea por el agotamiento y su figura se desvanece entre los árboles y llega a difuminarse su silueta negra con el decorado). En este momento concreto, las melodías de guitarra eléctrica y saxofón, instrumentos que con sus continuos diálogos dan movimiento a la escena, son los que representan a ambos personajes.

En referencia a la tercera y última secuencia, Tengo que convertirme en Caligari (duración: 1 h 1 min 19 s-1 h 3 min 21s), está bañada de las influencias de la teoría del psicoanálisis y la dualidad del ser. Respecto del contenido, se hace referencia al personaje Caligari y a su figura como doctor del manicomio que en su diario íntimo relata sus experiencias clínicas. Y es con este manuscrito donde queda evidencia que él no es quien realmente dice ser (falsa identidad). Se trata de un personaje enigmático que ha estudiado a fondo el sonambulismo y conoce la existencia de un doctor con el mismo nombre que se dedica a viajar por las ferias del norte de Italia, a principios del siglo XVIII, acompañado de un sonámbulo que comete crímenes bajo sus órdenes.

Ya en los antecedentes fílmicos de matiz expresionistas — citados al inicio del texto- era habitual la presencia de personajes que reflejaban la noción el otro yo. Así, en el caso de Der Student von Prag, un ser (el brujo/demonio Scapinelli) usurpa el alma de otra persona (estudiante Baldwin), y en Der Golem, la materia muerta (una estatua de arcilla) se convierte en materia viva (el cuerpo del golem). Y ese mismo tratamiento se contempla en Das Kabinett des Doktor Caligari cuando una persona (doctor Caligari) se apropia (por hipnosis) del cerebro (mente) de otra (el sonámbulo Cesare).

Al psiquiatra del manicomio se le presenta la oportunidad de llevar a cabo sus más horribles deseos reprimidos y esto lo hace motivado por esa voz interior que sale de su subconsciente que le persigue, atormenta y atrapa (estado de enajenación). En el fragmento, la imagen fílmica visibiliza sus deseos (el delirio) y lo hace con una composición de plano cargada de sobreimpresiones tipográficas variadas (tamaño, forma y textura) que adoptan distintas angulaciones (horizontal, diagonal, contradiagonal) que brotan (a modo de flash) y a un ritmo cada vez más frenético (el sumo de su alucinación). Y con esta estética al más puro estilo de las primeras vanguardias europeas se inscribe la frase mítica del film "Tengo que convertirme en Caligari". Para esta escena, el compositor Viertlböck recurre en su creación al empleo de instrumentos de diversa naturaleza, como son el sintetizador, el saxofón, la guitarra eléctrica, la batería, el bajo eléctrico y el piano (tabla 4). 
Tabla 4. Ficha musical de la secuencia $<<$ Tengo que convertirme en Caligari $>>$

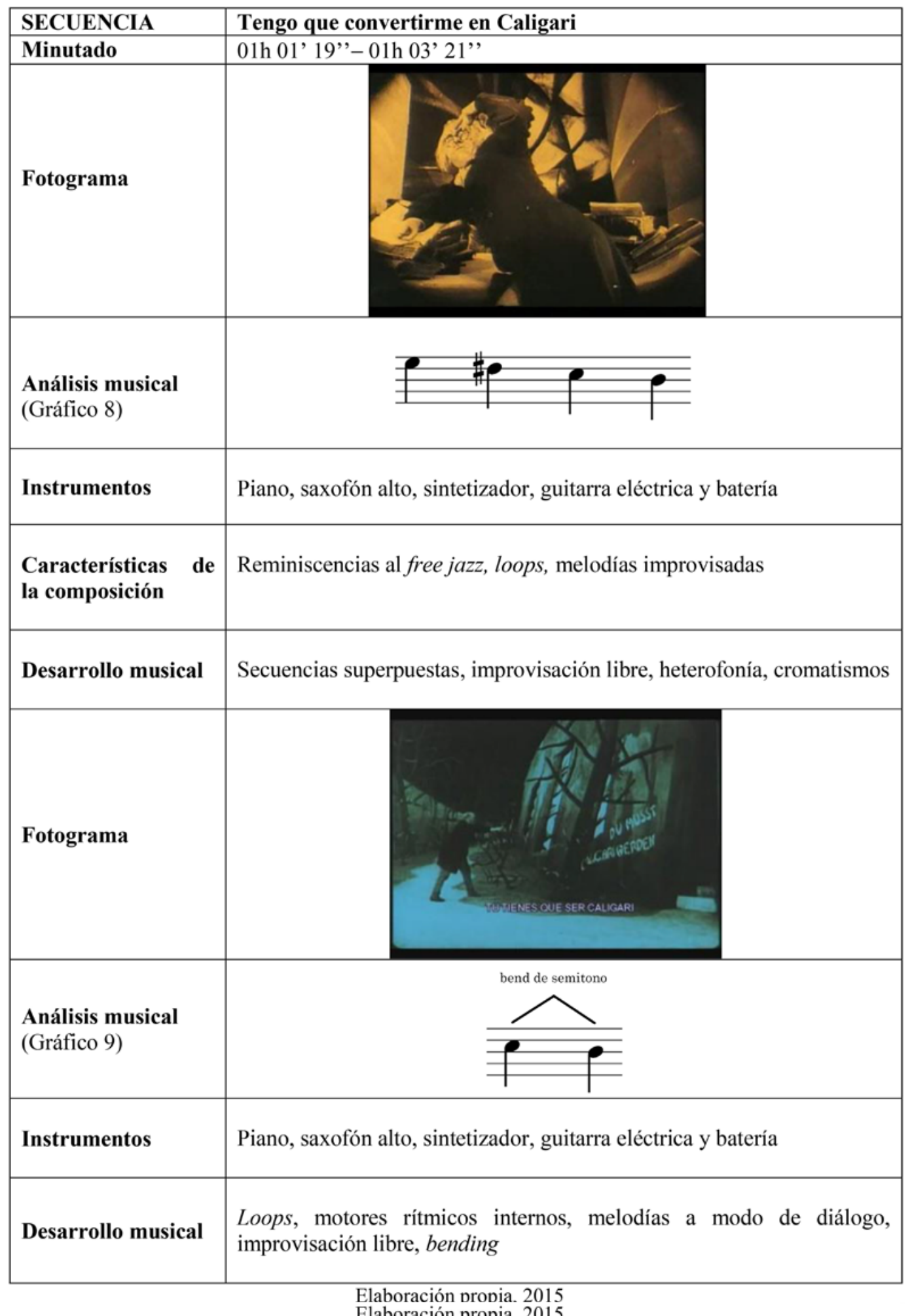

Elaboración propia, 2015 
La visión dramática de su mundo interior y el tema de la duda existencial del individuo (doctor Caligari) está representado musicalmente por secuencias superpuestas de elementos de improvisación libre, semejantes a una heterofonía, en la repetición de bases rítmicas y superposición de agregados de sonidos que sirven como colchón para dejar libertad creativa a los solistas. En estos momentos de locura (Caligari está perdiendo la cabeza, muestra su personalidad atormentada, la lucha con su mente y mundo interior que no controla), la música apoya esta sensación que puede entenderse como un diálogo con el subconsciente (su otro yo). La inestabilidad existencial del alma, del espíritu, se representa mediante la superposición de motivos rítmico-melódicos breves a modo de loops. El movimiento está representado por motores rítmicos internos a los que se superponen melodías improvisadas en forma de diálogo (gráfico 8).

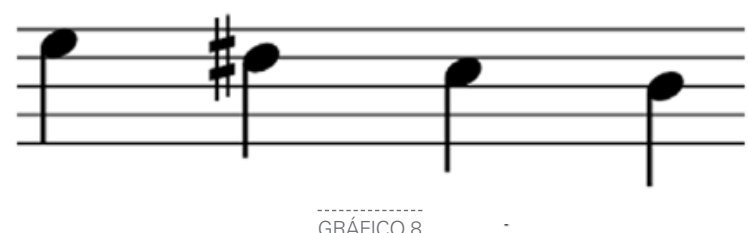

A partir de un ictus motívico inicial muy breve, se generan todos los elementos melódicos posteriores, en busca siempre los clímax de las frases. Más tarde, el piano hace su aparición (es la salida del doctor al exterior para intentar huir de sus propios pensamientos). Se podría confirmar de esta manera la idea que ya se apuntaba previamente en el análisis musical de la escena "La feria" (el personaje Caligari está representado por el piano). En este momento, con las improvisaciones de todos los instrumentos, se simboliza la batalla entre el bien y el mal (dualidad del ser), y en estas circunstancias el ritmo musical se vuelve cada vez más lento y contrasta fuertemente con la imagen dinámica que emana del plano, recargada de sobreimpresiones tipográficas (heterogéneo conjunto de fuentes, tamaños y formas de letras distintas, surgen y desaparecen, en horizontal y diagonal a ritmo distinto en los diversos ángulos del encuadre), con la frase mítica: "Quiero convertirme en Caligari" (aludiendo a esa voz interior que emana de las entrañas recónditas del subconsciente). Y esa variedad de estilo tipográfico está muy acorde con el contexto cultural, siendo reflejo de estética de los ismos y del espíritu de renovación creadora que supuso la Escuela Bauhaus creada por Walter Gropius, en Weimar en 1919 (Fiedler y Feierabend 2000).

El análisis estructural del entramado ideológico nos trae reminiscencias al free jazz que cierra el discurso musical y la escena con el sintetizador, en el registro agudo y un descuidado bending descendente en el saxofón (gráfico 9).

bend de semitono

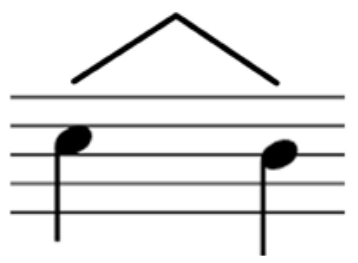

GRÁFICO 9 


\section{CONCLUSIONES}

Aunque este film, Das Kabinett des Doktor Caligari, de Robert Wiene (1919), abre el periodo del cine de Weimar, es significativo que en su estreno no se recurriese a música expresionista sino a compositores clásicos y románticos; hecho que no fue bien aceptado por la crítica y el público del momento. En esta situación, el productor de la UFA decidió encargar a Giuseppe Becce una composición específica para el film, cuya partitura desapareció.

Pues bien, a lo largo de estos casi cien años, ha habido intentos de reconstruir lo que podría haber sido la composición original y se han realizado versiones con diferentes estilos musicales. Pero, de todas ellas, se ha seleccionado para el estudio la composición de Rainer Viertlböck (1993), precisamente porque fue creada exclusivamente para la única versión íntegra restaurada del film que existe en la actualidad, realizada por Friedrich Wilhelm Murnau Stiftung y a cargo del Bundesarchiv film archive (Berlín).

En el estudio, vemos que la música de Viertlböck abandona los códigos heredados del romanticismo, posromanticismo e incluso de la música clásica, para adentrase en una banda sonora basada en el jazz, free jazz — por su gran cantidad de cromatismo que lleva en ocasiones hasta la atonalidad - y en la música improvisada que dota al film de mayor profundidad y aporta ritmo, dinamismo y movimiento. Esta película que narra la historia de un loco hace que la música de Rainer contribuya a visualizar y personificar esa locura (esa mente enferma que simboliza el caos social de la Alemania de posguerra). Así, las innumerables improvisaciones que se suceden plasman esos cantos del alma (los delirios del subconsciente del ser).

Viertlböck se sumerge en la historia del film y recurre a una instrumentación bastante peculiar basada en el piano, el saxofón alto, el sintetizador, la guitarra eléctrica, el teclado, el bajo eléctrico y la batería, cuya combinación provoca un resultado exageradamente efectista. Los leitmotivs son continuos e identifican instrumentos con personajes y sus acciones e, incluso, describen sus sentimientos. Estas influencias del leitmotiv wagneriano, utilizadas como una especie de etiqueta musical, asociadas a personajes que a veces sin estar visibles en escena, sirven para recordarnos su presencia. La asociación de instrumentos a personajes (el personaje Caligari está representado en el piano) y la repetición de motivos, no solo aportan unidad musical al relato fílmico, sino que se convierten en elementos narrativos (generadores de sentimientos de angustia y obsesión). De este modo, se establece una relación de simbiosis entre la trama (que consigue mayor presencia y notoriedad) y la música (que se reafirma como un elemento protagonista). En su creación, Viertlböck apuesta por que la música se relacione con todos y cada uno de los elementos que fluyen en la imagen de cada escena. De este modo, describe con motivos musicales los estados psíquicos inestables de los personajes, la naturaleza muerta de un paisaje urbano adulterado y la densa atmósfera de pesadilla que atrapa a los personajes.

La música tiende hacia formas tonales breves y condensa la atonalidad y el jazz. Una composición que, sin utilizar una banda sonora propiamente expresionista, que sería la música que le corresponde al periodo de la película (retroalimentada fuertemente por este movimiento en su puesta en escena pero no musicalmente), hace que la partitura de Viertlböck esté ciertamente influenciada por ese atonalismo de la época de Schönberg.

En su desarrollo musical de las frases, recurre a composiciones monotemáticas sobre secuencias acórdicas. Las intervenciones de saxofón suelen coincidir con escalas descendentes. Son continuas las aceleraciones de ritmo y se abusa de las dinámicas extremas. Es de gran importancia el uso de técnicas y efectos como loop, riff, delay o bending, al igual que los motores rítmicos internos.

\X' Cuadernos de Música, Artes Visuales y Artes Escénicas / Volumen 12 - Número 2 julio - diciembre de 2017 / ISSN 1794-6670/ Bogotá, D.C., Colombia / pp. xx 
La partitura de Viertlböck suele ofrecer al mismo tiempo dos planos sonoros distintos, el irreal (basado en la música electrónica, sintética, heredera de la tradición musical de la década de 1970 que experimenta con sintetizadores) y el real (con instrumentos de percusión) que suelen fundirse para crear sonoramente un ambiente claustrofóbico, vertiginoso y de inestabilidad (el mundo del lado oscuro de la mente). Y, en esos dos planos, los sonidos llegan a fusionarse con las onomatopeyas (efectos de abrir y cerrar puertas, de crujir de maderas al andar, etc.) que crean una sensación sonora caótica y un desorbitado ambiente sonoro (el mundo interior de los personajes y las situaciones de las que son prisioneros).

En otras ocasiones, su composición deja asomar instrumentos de viento con los de cuerda e irrumpe el saxofón alto y el piano (para una escena íntima y de dolor) que se identifican con los sentimientos de los personajes (el piano, con sus acordes repetitivos y lineales, distorsiona aún más las emociones, mientras que el saxo alto agudiza sus notas, hirientes, largas y distorsionadas).

\section{DISCUSIÓN}

La música en el Cine de Weimar es un campo muy poco investigado. A diferencia de la abundancia de estudios existentes desde otros ámbitos disciplinares, apenas existen contribuciones sobre la composición musical de estas películas y no se encuentran estudios músicofílmicos de la naturaleza que se presentan en esta contribución. Esta situación puede estar originada por la peculiaridad del periodo de producción (películas no sonoras estrenadas con una orquesta sinfónica in situ y en su distribución se optaba por música de acompañamiento no original) y las disfunciones habidas en su conservación (pérdida de la película virgen y de la partitura original, diversas mutilaciones en el montaje de la cinta, etc.).

Esta laguna existente en el campo de la musicología impulsó una investigación integral sobre la música en el cine de la República de Weimar que generó estudios en torno a los diversos films producidos en ese periodo, donde se han analizado detalladamente elementos estructurales (melódicos, armónicos, tímbricos, motívicos), recursos estilístico-estéticos que emanan de la música e imagen cinematográfica (fuente sonora, plano sonoro, funciones, etc.), así como los instrumentos utilizados en la composición musical.

Los resultados de la investigación se aportan a estudios de films concretos para un análisis profundo de la importancia del empleo de la música en el enriquecimiento del relato fílmico. Explorar esta/s película/s producida/s en el periodo de las primeras vanguardias europeas (con tantas posinfluencias temáticas, de género y estéticas referenciadas a posteriori en el campo de las artes visuales y escénicas), y además hacerlo con la extremada propuesta creativa de Viertlböck, es un reto científico. Los sentimientos que emana la imagen cinematográfica, Rainer los ha sabido plasmar formidablemente en una partitura moderna con notas musicales muy acordes con la estética del cine de la República de Weimar, pero en un contexto creador de la década de 1990. Una banda sonora que combina armónicamente música e imagen cinematográfica. 


\section{NOTAS}

1 DVD. Divisa Home Video, Valladolid, 2003.

\section{REFERENCIAS}

Alsina, Pep y Frederic Sesé. 1997. La música y su evolución: historia de la música. Barcelona: Graó. Ashworth, Peter D. 2000. "Métodos cualitativos de investigación”. Estudio Pedagógico 26: 91-106.

Barlow, John D. 1982. German Expressionist Film. Boston: Twayne.

Beltrán, Rafael. 1984. La ambientación musical: selección, montaje y sonorización. Madrid: Instituto Oficial de Radio y Televisión.

Berendt, Joachim E. 1993. El jazz de Nueva Orleáns a años ochenta. Madrid: Fondo de Cultura Europea.

Berriatúa, Luciano. 1990. Los proverbios chinos de F.W. Murnau. 2 vols. Madrid: Filmoteca Española.

Chion, Michel. 1997. La música en el cine. Barcelona: Paidós.

Colón, Carlos, Fernando Infante y Manuel Lombardo. 1997. Historia y teoría de la música en el cine: presencias afectivas. Sevilla: Alfar.

Courtade, Francis. 1984. Cinéma expresionniste. París: Henri Veyrier.

Eisner, Lotte H. 1996. La pantalla demoníaca: las influencias de Max Reinhardt y del expresionismo. Madrid: Cátedra.

Escudero, Jesús, Luis A. Delfín y Leonor Gutiérrez. 2008. “El estudio de caso como estrategia de investigación en las ciencias sociales". Revista de Ciencia Administrativa 1: 7-10.

Fernández, Carlos. 1961. El cine alemán: elementos de filmografía crítica (1896-1960). Madrid: Filmoteca Nacional de España.

Fiedler, Jeannine y Peter Feierabend, coords. 2000. Bauhaus. Colonia: Könemann.

Francis, André. 1972. Panorama del jazz. Caracas: Tiempo Nuevo.

Gertrudix, Manuel. 2003. Música y narración en los medios audiovisuales. Madrid: Laberinto Comunicación.

Goffin, Robert. 1958. Historia del jazz. Buenos Aires: Cenit.

Gombrich, Ernst H. 1992. Historia del arte. Madrid: Alianza.

Grignaffini, Giovanna y Leonardo Quaresima. 1978. Cultura e cinema nella Repubblica di Weimar. Venecia: Marsilio Editori.

Gersch, Wolfgang. 1975. "Expressionnisme et cinema". Obliques 6-7 (especial L'expressionnisme allemande. Coord. L. Richard): 153-161.

Gubern, Román. 1992. Historia del cine. Vol. 1. Barcelona: Baber.

Güller, Lorenzo. 2010. “El expresionismo alemán y la música". Creación y Producción en Diseño y Comunicación 35: 85-88.

Hall, Ben. 1987. The Best Remaining Seats. Nueva York: Clarkson Potter.

Hernández, Javier. 1990. Escenarios de la fantasía: el legado de la arquitectura y de las artes plásticas en el cine. Zaragoza: Universidad de Zaragoza y Filmoteca Municipal.

i Falcó, Josep Lluís. 1995. "Paràmetres per a una anàlisi de la banda sonora musical cinematogràfica". D'Art: Revista del Departament d'Història de l'Art 21: 169-186.

Konigsberg, Ira. 2004. Diccionario técnico Akal de cine. Madrid: Akal.

Kracauer, Siegfried. 1985. De Caligari a Hitler: una historia psicológica del cine alemán. Barcelona: Paidós. Lack, Russell. 1999. La música en el cine. Madrid: Cátedra.

'XX' Cuadernos de Música, Artes Visuales y Artes Escénicas / Volumen 12 - Número 2 julio - diciembre de 2017 / ISSN 1794-6670/ Bogotá, D.C., Colombia / pp. xx 
Mitry, Jean. 1974. "Futurisme expressionisme et cinéma". En Le cinema expérimental: histoire et perspectives, 26-62. París: Seghers.

Morgan, Robert P. 1999. La música del siglo XX. Madrid: Akal.

Murphy, Richard. 1999. Theorizing the Avant-Garde: Modernism, Expresionism, and the Problem of Postmodernity. Cambridge: Cambridge University Press.

Navarro Arriola, Heriberto y Sergio Navarro Arriola. 2003. Música de cine: historia y coleccionismo de bandas sonoras. Madrid: Ediciones Internacionales Universitarias.

Nieto, José. 1996. Música para la imagen: la influencia secreta. Madrid: SGAE.

Panassié, Hugues. 1961. Historia del verdadero jazz. Barcelona: Seix Barral.

Pladevall Fontanet, Tomás. 1997. "Estilos de iluminación cinematográfica". Anuario AEC, 19951996. Madrid.

Pombo, Fátima. 2001. Trazos de música. Pontevedra: Diputación Provincial.

Rancan, Luigino. 2012. Giuseppe Becce: Musica per il cinema Contributo alla biografia del primo compositore di musiche per Cinema. Lonigo: Istituto Musicale Sergio Lorenzi.

Reale, Giovanni y Darío Antiseri. 1988. Historia del pensamiento filosófico y científico. T. 3. Barcelona: Herder.

Riemann, Hugo. 1928. Teoría general de la música. Barcelona: Labor.

Richard, Lionel. 1979. Del expresionismo al nazismo: arte y cultura desde Guillermo II hasta la República de Weimar. Barcelona: Gustavo Gili.

Sadie, Stanley. 1995. La guía Akal de la música. Madrid: Akal.

Sánchez-Biosca Vicente. 1985. Del otro lado: la metáfora. Modelos de representación en el cine de Weimar. Valencia: Instituto de Cine y Radio-Televisión/Hiperión.

- 1990. Sombras de Weimar, contribución a la historia del cine alemán 1918-1933. Madrid: Verdoux.

Sierra Bravo, Restituto. 1983. Técnicas de investigación social. Madrid: Paraninfo.

Tirro, Frank. 2001. Historia del jazz clásico. Barcelona: Robinbook.

- 2001. Historia del jazz moderno. Barcelona: Robinbook.

Willett, John. 1970. Expressionism. Londres: Weidenfeld \& Nicolson.

Xalabarder, Conrado. 2006. Música de cine: una ilusión óptica. LibrosEnRed.

\section{FILMOGRAFÍA}

Das Kabinett des Doktor Caligari (Robert Wiene, 1919). Versión musical: Rainer Viertlböck. Edición: versión íntegra restaurada (Friedrich Wilhelm Murnau Stiftung). [DVD]. Divisa Home Vídeo, Valladolid, 2003.

\section{Cómo citar este artículo:}

Amorós Pons, Anna María \& Gómez Otero, Nuria. 2017. "La música de Rainer Viertlböck en la versión restaurada del film Das Kabinett des Doktor Caligari, de Robert Wiene (1919)". Cuadernos de Música, Artes Visuales y Artes Escénicas 12 (2): xx-xx. [https://doi:10.11144/Javeriana.mavae12-2.mrvv]https:// doi:10.11144/Javeriana.mavae12-2.mrvv 